\title{
Comparing Teen Substance Use in Northern New Hampshire to Rural Use Nationwide
}

$\mathrm{R}$ ecent national estimates show that rates of substance use disorder are essentially the same for rural (nonmetropolitan) and urban (metropolitan) teens, with one exception: rural teens are nearly twice as likely to suffer from tobacco dependence than their urban counterparts. ${ }^{1}$ It is not known, however, how substance use patterns among teens in rural New Hampshire compare to rural teens nationwide. In an effort to compare teen substance use patterns in New Hampshire's most rural county to patterns among rural youth nationwide, this brief uses data from two surveys administered in 2011.

The first survey, the Coös Youth Study (CYS), is a study of youth who completed paper-and-pencil questionnaires in rural Coös County's public middle and high schools in 2008 or 2009 , and who were surveyed again in $2011{ }^{2}$ For this brief, the analyses focus on 313 teenagers, ages 15 to 17 , who completed questionnaires in 2011 and provided complete data on substance use patterns. ${ }^{3}$ The second survey, the National Survey on Drug Use and Health (NSDUH), is a nationally representative survey based on computer assisted self-interviews with non-institutionalized civilians residing in the United States. ${ }^{4}$ For this brief, the analyses focus on the 2,138 adolescent respondents, ages 15 to 17, who were living in non-metropolitan areas in 2011 and who provided usable data on substance use patterns. ${ }^{5}$

Figure 1 shows the percentages of adolescents in Coös and in rural areas nationwide who reported using alcohol, tobacco, marijuana, other illicit drugs, and any substances in the prior year. As shown, about half of the teens in Coös and in rural areas nationwide reported using any substance in the previous year (ranging from 49 to 56 percent). Alcohol use was reported most often, followed by tobacco or marijuana, and other illicit substances.

Notably, the use of tobacco was highest among rural boys nationwide; in fact, rural boys nationwide were significantly more likely than rural girls nationwide or Coös girls and boys to use tobacco in the prior year. Yet, as Figure 2 shows, the frequent use of substances in the prior year tells a different story. In Figure 2, the percentages of teenagers in Coös and in rural areas nationwide who reported using substances "three to four times weekly" or more in the prior year are presented. Substances include alcohol, marijuana, other illicit drugs, or any substance. ${ }^{6}$

\section{Key Findings \\ - Compared to same-aged rural teens nationwide, Coös County teens were less likely to report the use of tobacco. \\ - Alcohol was the substance most likely to be used by all rural teens surveyed, yet among substance users, marijuana was used most frequently. \\ - Compared to other rural teens, Coös boys were twice as likely to have used marijuana three times weekly or more. \\ - Coös teens were more likely than the national rural sample to report problems with family members or friends due to their substance use.}

FIgURE 1. EXCEPT FOR TOBACCO USE, RURAL TEENS IN CoÖs COUNTY AND NATIONWIDE REPORTED SIMILAR PERCENTAGES OF SUBSTANCE USE IN THE PRECEDING YEAR

- Any Substance $\square$ Alcohol $\square$ Tobacco $\square$ Marijuana $\square$ Other Illicit Drug

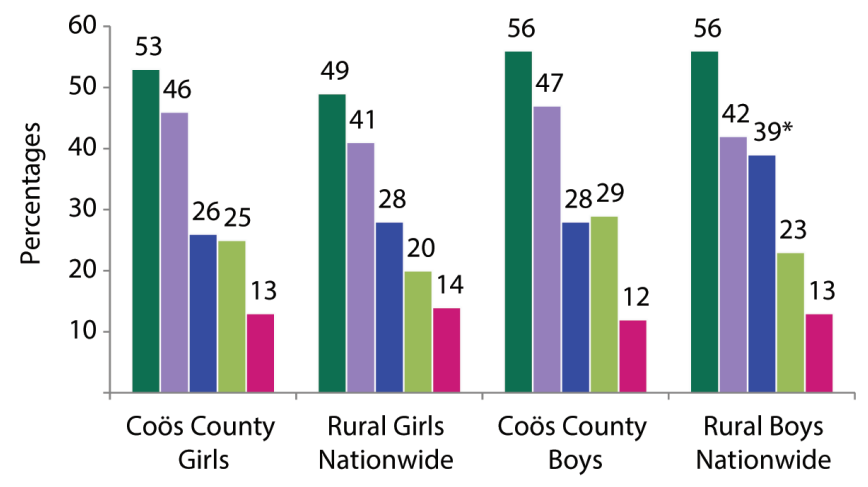

Note: ${ }^{*}$ Rural boys nationwide reported using tobacco at significantly higher rates $(p<.001)$ than Coös boys and girls and rural girls nationwide. 
Figure 2. Coös County boys Reported the highest PERCENTAGES OF SUBSTANCE USE, ESPECIALLY MARIJUANA USE, "THREE TO FOUR TIMES WEEKLY" OR MORE IN THE PRECEDING YEAR

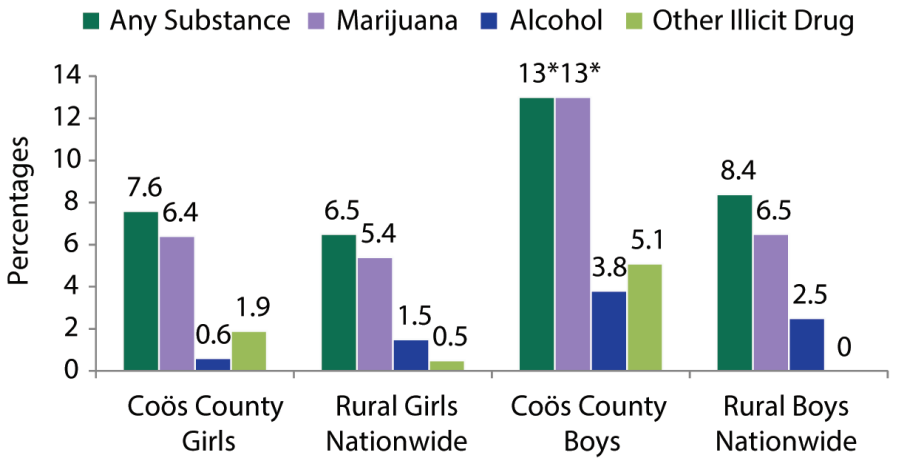

Note: ${ }^{*}$ Coös boys reported significantly higher rates of frequent use (that is, three or more times weekly) of marijuana $(p<.01)$ or any substance $(p<.05)$ than Coös girls and rural boys and girls nationwide.

As shown, the most frequently used substance in Coös and in rural areas nationwide was marijuana, and Coös boys were twice as likely as Coös girls or rural teens nationwide to report using marijuana three times or more per week in the past year. ${ }^{7}$ Prior research has shown that teen marijuana use is related to youth stress exposure, which increases risk for other illicit drug abuse in young adulthood. ${ }^{8}$ Strategies that ease Coös teens' stress could thus reduce current and subsequent drug problems, especially for males.

Figure 3 presents the percentages of teens in Coös and in rural areas nationwide who reported experiencing at least one of nine substance abuse symptoms in the prior year, as well as the three most reported symptoms. Coös teens reported significantly more substance abuse symptoms than did rural teens nationwide. ${ }^{9}$ Coös teens were more likely to report that, in the preceding year, their substance use caused problems with their friends or family or that they were "under the influence" when they could have gotten hurt. Equal percentages of teens in Coös and rural areas nationwide reported that they wanted to quit or cut down on their substance use.

In summary, Coös teens are less likely to use tobacco than rural teens nationwide. Yet, Coös boys do appear to use marijuana more frequently than their national counterparts, and Coös teens report higher rates of substance abuse symptoms. Previous research has shown that teens who use marijuana are more "stressed out," and that such stress can increase their risk for other illicit drug abuse in young adulthood. ${ }^{10}$ In addition, research on Coös County teens has shown that stress exposure increases risk for problem substance use one year later, ${ }^{11}$ even when accounting for previous substance use problems. ${ }^{12}$ That is, it appears that stress exposure increases risk for substance use problems rather than the reverse. Early exposure to
FigURE 3. COMPARED TO RURAL TEENS NATIONWIDE, Coös County teens Reported higher PERCENTAges OF SUBSTANCE ABUSE SYMPTOMS IN THE PRECEDING YEAR

- Reported at least one of nine substance abuse symptoms

- Wanted to quit or cut down on substance use

- Use caused problems with friends or family

Under the influence when could have gotten hurt

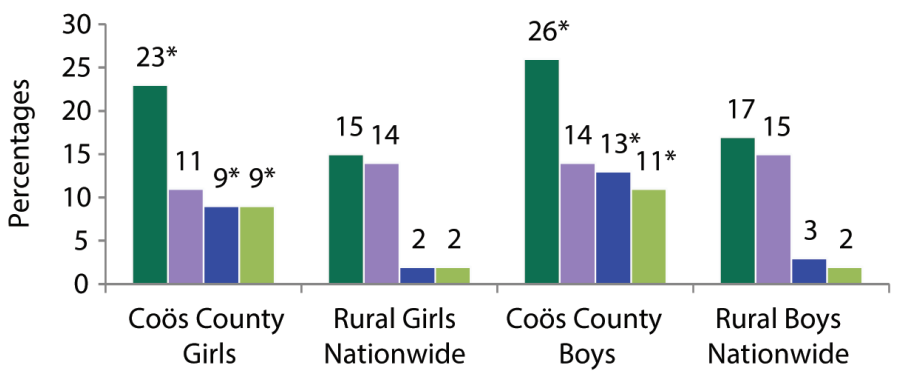

Note: ${ }^{*}$ Asterisks denote statistically significant differences $(p<.01)$ between Coös teens and rural teens nationwide. No sex differences in substance abuse symptoms were observed.

stress also raises risk for other indicators of suffering in young adulthood, such as depressed mood and criminal behavior. ${ }^{13}$ As such, substance abuse policies and practices that prevent, reduce, or buffer the stresses faced by Coös teens can also enhance their general well-being as they make the transition to adulthood.

\section{E N D N O T E S}

1. Karen T. Van Gundy and Meghan L. Mills, "Health and the Stress Process in Rural America," in Poverty and Health, A Crisis Among America's Most Vulnerable, Volume 2: The Importance of Place in Determining their Future, edited by Kevin M. Fitzpatrick (Santa Barbara, CA: Praeger, 2013).

2. See Eleanor M. Jaffee, “Coös County’s Class of 2009: Where Are They Now?” Issue No. 31 (Durham, NH: Carsey Institute, University of New Hampshire, 2012); Nena F. Stracuzzi, "Youth Aspirations and a Sense of Place in a Changing Rural Economy: The Coos Youth Study," Issue No. 11 (Durham, NH: Carsey Institute, University of New Hampshire, 2009); Corinna Jenkins Tucker et al., "Sibling Proactive and Reactive Aggression in Adolescence," Journal of Family Violence 28 (2013): 299-310; Karen T. Van Gundy et al., "Perceived Community Cohesion and the Stress Process in Youth," Rural Sociology 76 (2011): 293-318.

3. Ninety-one percent of the Coös teens in this sample are non-Hispanic White, compared to 73 percent nationwide, and prior research has shown that race/ethnicity is related to substance use behaviors. Thus, significance tests in this brief adjust statistically for these differences. Age, which also contributes to substance use patterns, is controlled statistically in the analyses as well. 
4. Respondents' perceived lack of anonymity or privacy in face-to-face interviews may lead to lower estimates of illegal behaviors, like underage or illicit substance use, compared to in-class surveys like the CYS. To reduce this potential bias, the NSDUH utilizes computer-assisted techniques that afford respondents a level of privacy akin to in-class surveys. As stated in the 2011 NSDUH codebook, "Use of [audio computer-assisted self-interviewing] is designed to provide respondents with a highly private and confidential means of responding to questions and to increase the level of honest reporting of illicit drug use and other sensitive behaviors." Still, comparisons of CYS and NSDUH estimates should bear in mind this potential reporting bias.

5. All NSDUH analyses presented in this brief are based on weighted data.

6. Due to differences in the CYS and NSDUH survey questions about tobacco use, analyses here do not examine differences in tobacco use frequency between the Coös County youth and rural youth nationwide.

7. In the CYS, respondents were asked how often in the past year they used alcohol, marijuana, inhalants/whippets, stimulants/uppers, pills/painkillers, or other illicit drugs. Response choices included "no times," "1-2 times," "3-5 times," "1-3 times per month," "1-2 times per week," “3-4 times per week," or "nearly every day." For purposes of this brief, frequent users included those who reported use "3-4 times per week" and "nearly every day." Frequent drug use in the NSDUH included respondents who reported using alcohol, marijuana, cocaine, hallucinogens, inhalants, or stimulants 156 or more days in the previous twelve months. As such, differences in the CYS and NSDUH estimates may derive, in part, from differences in the survey instruments.

8. Karen Van Gundy and Cesar J. Rebellon, "A Life-Course Perspective on the "Gateway Hypothesis," Journal of Health and Social Behavior 51 (2010): 244-59.

9. Only Coös teens reporting a substance abuse symptom "sometimes" or "often" in the prior year were counted as experiencing the symptom.

10. Karen Van Gundy and Cesar J. Rebellon, "A Life-Course Perspective on the 'Gateway Hypothesis.”

11. Karen T. Van Gundy and Meghan L. Mills, “Teen Stress and Substance Use Problems in Coös: Survey Shows Strong Community Attachment Can Offset Risk," Issue Brief No. 29 (Durham, NH: Carsey Institute, University of New Hampshire, 2011).

12. Meghan L. Mills and Karen T. Van Gundy, "Socioeconomic Status and the Stress Process in Rural Youth: The Role of Social Attachments" (presented at the annual meeting of the American Sociological Association, Denver, CO, August, 2012).
13. Karen Van Gundy. "Gender, the Assertion of Autonomy, and the Stress Process in Young Adulthood," Social Psychology Quarterly 65 (2002): 346-63.

\section{A BOUT THE AUTHOR}

Karen T. Van Gundy is an associate professor of sociology, a core member of the Justice Studies faculty, and a faculty fellow at the Carsey Institute at the University of New Hampshire (karen.vangundy@unh.edu).

\section{A C KN O W L E D G E M E N T S}

The National Survey on Drug Use and Health, which is made available by the Inter-University Consortium for Political and Social Science, is supported by the Substance Abuse and Mental Health Services Administration and the U.S. Department of Health and Human Services. The Coös Youth Study is supported by the National Science Foundation (Grant No. 1155797) and the Neil and Louise Tillotson Fund of the New Hampshire Charitable Foundation (Grant No. 79127). Any opinions, findings, conclusions, or recommendations expressed in this brief are those of the author and do not necessarily reflect the views of the funders. This work relies also on the generous participation of the respondents, their families, teachers, school officials, and the communities involved in the Coös Youth Study. Special thanks go to Meghan Mills and Michael Staunton, who have been crucial to the ongoing success of this project, and to Bruce Mallory, Curt Grimm, Laurel Lloyd, Beth Mattingly, and Amy Sterndale of the Carsey Institute for their helpful comments and suggestions. 


\section{The Carsey Institute Coös Youth Study}

The Carsey Institute is conducting a panel study of Coös County youth that will provide data about the attitudes and experiences of the county's youth as they approach young adulthood and face the decision to remain in their community, seek opportunities elsewhere, or leave for an education and then return. By following the entire populations of two age groups over a ten-year period, we will help North Country leaders gain a better understanding of young people's decision making.

\section{Research Team}

Eleanor M. Jaffee is an evaluation research associate at the Carsey Institute and research assistant professor of social work. She provides program evaluation and project management for the Coös Youth Study, as well as technical assistance to organizations seeking to build internal capacity for evaluation. Her dissertation research focused on the quality of life of women enrolled in a supported housing program for adults with psychiatric disabilities and histories of homelessness.

Cesar J. Rebellon is a faculty fellow at the Carsey Institute and an associate professor in sociology at the University of New Hampshire. His primary research interests focus on family and peer correlates of juvenile crime and delinquency, with a particular emphasis on the manner in which delinquency may yield reinforcing social rewards among adolescents.

Erin Hiley Sharp is a Carsey Institute faculty fellow and assistant professor in family studies at the University of New Hampshire. Her research interests include activity involvement as a context for adolescent development; parental, family, and broader contextual influences on adolescent development; and prevention research and theory from a positive youth development perspective.

Nena F. Stracuzzi is a senior teaching and research fellow in the doctorate of education program at Northeastern University and a faculty fellow at the Carsey Institute. Her research for the Carsey Institute has focused primarily on vulnerable youth and families.

Corinna Jenkins Tucker is a faculty fellow at the Carsey Institute and an associate professor in family studies at the University of New Hampshire. Her primary research interests focus on the nature and context of family relationships and their links to adolescent psychosocial development.

Karen T. Van Gundy is an associate professor of sociology, a core member of the Justice Studies faculty, and a faculty fellow at the Carsey Institute at the University of New Hampshire. Her work applies 'stress process' and 'life course' approaches to understanding place-linked variations in physical, emotional, and behavioral health outcomes over time.

\section{A of NEW HAMPSHIRE \\ CARSEY}

Building knowledge for families and communities

The Carsey Institute conducts policy research on vulnerable children, youth, and families and on sustainable community development. We give policy makers and practitioners timely, independent resources to effect change in their communities.

This work was supported by the The Neil and Louise Tillotson Fund of the New Hampshire Charitable Foundation.

Huddleston Hall

73 Main Street

Durham, NH 03824

(603) 862-2821

www.carseyinstitute.unh.edu 